\title{
Foraminifera recycling in worm reefs
}

Received: 7 May 2009/ Accepted: 4 June 2009/Published online: 26 June 2009

(C) Springer-Verlag 2009
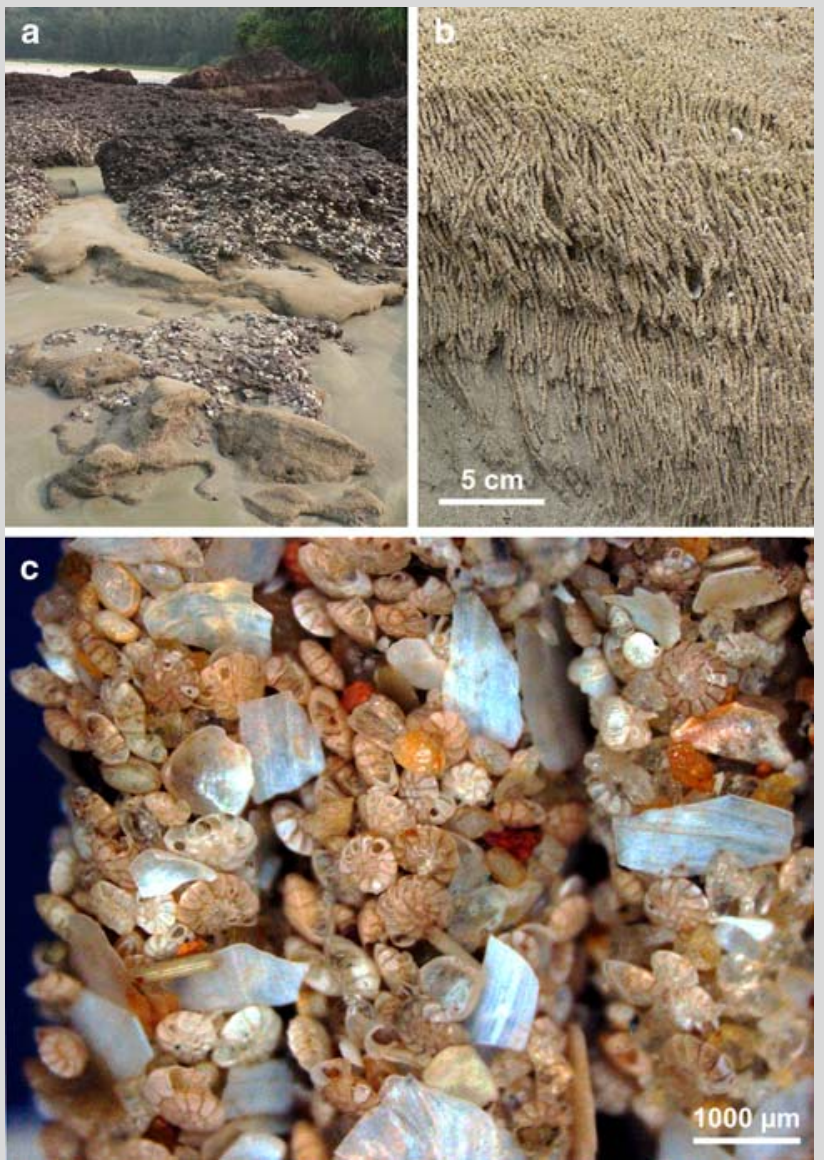

Fig. 1 a Worm reefs on laterite blocks in the intertidal zone at Meenkunnu Beach. b The build-ups are constructed by densely packed and loosely joined tubes $20 \mathrm{~cm}$ in length. $\mathbf{c}$ Close-up of agglutinated worm tubes dominated by Ammonia beccarii tests
Sabellarid annelids accrete reefs in intertidal and subtidal zones of temperate to tropical seas at places where heavy wave- and current-action cause the suspension and transport of sand-sized particles (Kirtley 1994). The sand grains are utilized for the construction of rigid agglutinated tubes which form the so-called "sandstone reefs". Tube construction involves a sorting process. Idanthyrsus bihamatus (Caullery, 1944) from Indonesia, for instance, is noted for preferring soritid foraminifera (Kirtley 1994), while Neosabellaria clandestina (Menon and Sareen, 1966) accumulate platy shell fragments and heavy minerals in their tubes at localities in southern India (Badve 1996).

Herein, we report on a case of foraminifera recycling from newly discovered worm reefs in SW-India (Meenkunnu Beach, N $11^{\circ} 54^{\prime} 38^{\prime \prime}$, E $075^{\circ} 19^{\prime} 09^{\prime \prime}$; Fig. 1a). At this place $N$. clandestina build-up cushion-shaped reef on rocky substrates in the surf zone and Sabellaris chandraae de Silva, 1961 forms thin veneers above these build-ups at the high tide level. Even though the flanking sediment is heavy mineral rich quartz sand with only $3 \% \mathrm{CaCO}_{3}$, the tubes of both species (Fig. 1b) contain high quantities of detritic carbonate $(65 \%)$. Remarkably more than $80 \%$ of these carbonate grains are tests of the rotaliid foraminifera Ammonia beccarii (Linnaeus, 1758) (Fig. 1c). In contrast, foraminifera (A. beccarii, Nonion sp., miliolids) are under-represented carbonate particles in the surrounding mobile beach sand where platy mollusc shell debris prevails.

This is the first observation of preferential foraminifera mounting in $N$. clandestina and $S$. chandraae tubes. It implies that the composition of worm reefs in high energetic settings is neither primarily controlled by the quantitative composition of the surrounding sediment nor specific to the biology of individual sabellarid species. In order to speculate about the concentration of foraminiferal tests in worm tubes, this may primarily be dependent on the local hydrodynamic regime that accounts for density fractionation of the suspended sand grains.

Acknowledgment Funding by the FWF through grant P-18189N10 is gratefully acknowledged.

References

Badve RM (1996) Observations on polychaete genus Sabellaria along the south and west coast of India. Curr Sci 70:402-405

Kirtley DW (1994) A review and taxonomic revision of the family Sabellariidae Johnston, 1865 (Annelida; Polychaeta). Sabecon Press, Science Series vol 1, Vero Beach, Florida

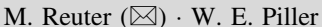

Institute of Earth Sciences, Graz University, Heinrichstr. 26, 8010 Graz, Austria

e-mail: markus.reuter@uni-graz.at

A. Kroh · M. Harzhauser

Paleontological and Geological Department, Natural History Museum Vienna, Burgring 7, 1010 Vienna, Austria

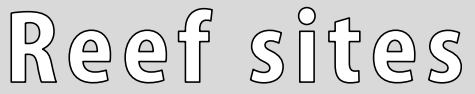

Coral Reefs (2010) 29:57

DOI $10.1007 / \mathrm{s} 00338-009-0523-7$ 